\title{
"Estimates of global terrestrial isoprene emissions using MEGAN (Model of Emissions of Gases and Aerosols from Nature)" published in Atmos. Chem. Phys., 6, 3181-3210, 2006
}

\section{A. Guenther}

Atmospheric Chemistry Division, National Center for Atmospheric Research, 1850 Table Mesa Drive, Boulder Colorado, 80305, USA

The purpose of this corrigendum is to document typographical errors in Eqs. (11) and (18) of the manuscript, "Guenther, A., Karl, T., Harley, P., Wiedinmyer, C., Palmer, P., and Geron, C.: Estimates of global terrestrial isoprene emissions using MEGAN (Model of Emissions of Gases and Aerosols from Nature), Atmos. Chem Phys., 6, 3181-3210, 2006"

Equation (11b) should have a minus sign before " $0.9 \phi^{2}$ " instead of the multiplication operator that is in the published manuscript. For the conditional on Eq. (11), modelers may prefer to use " $\sin (a)<0$ " rather than the " $0<a<180$ " given in the published manuscript since this eliminates the need to calculate the angle "a".
The correct equation is:

$\gamma_{P}=0 \quad$ for $\sin (a)<0$

$\gamma_{P}=\sin (a)\left[2.46\left(1+0.0005 \times\left(P_{\text {daily }}-400\right)\right) \phi-0.9 \phi^{2}\right]$

for $\sin (a)>0$

The conditional statement for Eqs. (18a) and (18b) should refer to " $T_{t}$ " rather than " $t_{i}$ " in the published manuscript. The correct equation is:

$$
\begin{array}{ll}
t_{i}=5+\left(0.7 \times\left(300-T_{t}\right)\right) & \text { for } T_{t}<=303 \\
t_{i}=2.9 & \text { for } T_{t}>303
\end{array}
$$

Correspondence to: A. Guenther

(guenther@ucar.edu)

Published by Copernicus Publications on behalf of the European Geosciences Union. 